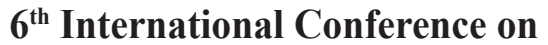 EARTH SCIENCE AND CLIMATE CHANGE September 18-19, 2017 Hong Kong
}

\section{A practical approach to $\mathrm{CO}_{2}$ sequestration: Reactions with high salinity water}

\section{Muftah H El-Naas}

Qatar University, Qatar

\begin{abstract}
arbon dioxide is known to be a major contributor to global warming and climate change and hence has an adverse effect on environmental sustainability. $\mathrm{CO}_{2}$ is emitted by various activities associated with industrial processes and the burning of various types of carbonaceous fuels such as coal, oil and gas. Over the past few years, there has been a considerable amount of interest in carbon capture and storage (CCS) as an option to mitigate the harmful effects of $\mathrm{CO}_{2}$ emissions. This study evaluates a new approach to the capture and sequestration of $\mathrm{CO}_{2}$ through reactions with high salinity water in the presence of an alkaline agent. Processes such as the Solvay process have been successful in utilizing the reactions of $\mathrm{CO}_{2}$ with ammoniated high salinity water to sodium bicarbonate. This process, however, suffers from several drawbacks such as inefficient contact mechanism and the need for the regeneration of ammonia as alkaline catalyst in the process. Such drawbacks have been addressed through developing a new, inert particles reactor system that offers efficient mixing and stable operation. At the same time, carbon dioxide is reacted with high salinity water in the presence calcium hydroxide instead of ammonia to provide the alkalinity needed for the reaction of $\mathrm{CO}_{2}$ and $\mathrm{NaCl}$. The new process and reactor system were able to achieve high $\mathrm{CO}_{2}$ capture efficiency (up to 99\%) and effective reduction in water salinity (up to 40\%), while storing the $\mathrm{CO}_{2}$ in a stable solid form, namely sodium bicarbonate. The new process can utilize any alkaline solid waste and the inert particles reactor system can be used to capture $\mathrm{CO}_{2}$ from different sources such as natural gas or flue gas.
\end{abstract}

\section{Biography}

Muftah H El-Naas is a QAFCO Chair Professor in Chemical Process Engineering at the Gas Processing Center, College of Engineering, Qatar University. He has completed his BASc degree in Chemical Engineering from the University of British Columbia, Canada, MEng and PhD in Chemical Engineering from McGill University, Canada. He has previously served as Chair of the Chemical and Petroleum Engineering Department, Director of the Petroleum Science and Engineering Graduate Program and Director of Research Funding at the UAE University. He has authored more than 150 papers in international journals and conferences, in addition to several book chapters and patent applications. His area of expertise includes $\mathrm{CO}_{2}$ capture and sequestration, biotechnology, water treatment and purification, membrane separation and plasma technology. Most of his recent research work focuses on the development of new, environmental-friendly technologies for the oil and gas industry.

\section{Notes:}

